\title{
FORMAÇÃo E ATUAÇÃo DO PROFISSIONAL EM EDUCAÇĀo FÍSICA ESCOLAR
}

\author{
Wagner Wey MOREIRA*
}

E interessante notar que, quando participamos de encontros como este, onde se trata da Educação Física Escolar, muitas questões são levantadas e problemas são colocados, todos eles passando direta ou indiretamente pela análise da "Formação e Atuação Profissional em Educação Física Escolar", tema da nossa mesa redonda. Também temos a tendência, nestes encontros, de não olharmos a história dos movimentos já ocorridos, dando a impressão de estarmos discutindo o tema pela primeira vez, sem levarmos em conta a ação cumprida pela Educação Física Escolar ao longo do tempo.

Queremos restringir nossa participação nesta mesa optando por analisar a atuaçâo profíssional do professor de Educação Física na escola. Esta tomada de posição se justifica por duas principais razôes: primeira, não cremos que os problemas dessa ação estejam vinculados às questốes de conteúdo programático "strictu sensu", como tentaremos provar; segundo, vamos estruturar nossa fala nos resultados de recente pesquisa empreendida junto ao dia-a-dia de professores de Educação Física na escola.

A Pesquisa sobre a "Ação do Professor de Educação Física na Escola", realizada no primeiro semestre de 1989, apresentou resultados que podem não ser novidade, mas não deixam de ser preocupantes. Após a análise ideográfica da ação dos sujeitos, professores licenciados em escolas diferentes e em épocas difcrentes, chegamos a uma convergência dc $100 \%$ em suas atitudes em onze itens principais, a saber:

1. Atitudes formais e autoritárias na relação com os alunos.

2. Educação Física como cumprimento mecânico e rigoroso do exercício.

3. O corpo visto como um objeto a ser melhorado em seu rendimento.

4. Atividades físicas propostas, muitas vezes, não adequadas ao desenvolvimento dos alunos.

5. As aulas estruturadas no esporte competitivo, praticado no rigor de suas leis.

6. $\mathrm{Na}$ competição, sempre presente, o sentido individualista prevalecendo sobre o sentido da cooperação.

7. Nas aulas, identificação clara de ausência da ludicidade e do prazer na ação dos alunos.

8. A Educação Física identificada como um produto acabado e não como um processo educativo.

9. No esporte, deve-se buscar a vitória a qualquer preço.

10. Nas aulas, busca-se o ritmo uniforme através dos exercício padronizados.

11. As aulas de Educação Física dependentes de fatores atmosféricos.

A pesquisa revelou esse quadro, que em altima análise, é um quadro de atitudes, mais precisamente, um quadro de $100 \%$ de convergência de atitudes, o que nos motivou a empreender uma análise desse fenômeno, considerando cinco questōes principais:

*Faculdade de Educação Física da Universidade Estadual de Campinas. 


\section{AS QUESTÕES DE FORMA E RITMO}

O elevado grau de convergência passa a idéia de que a formação profissional em Educação Física é realizada em série, como por exemplo, uma eficiente montadora de automóveis, onde no final da linha de produção temos um produto acabado. Isto, evidentemente, revela atitudes dos profissionais agentes de formação.

Os sujeitos da pesquisa não se preocuparam, em suas ações, cm legitimar o espaço da Educação Física na escola ${ }^{2}$

O cumprimento formal de ordem, a obediência inquestionável da realização de exercícios através de um ritmo padronizado e único, em nenhum momento privilegia a ação educativa que se preocupa com a visão do ser humano que é uno, que se movimenta intencionalmente, que brinca e que é
sensível.

Para não utilizarmos as aulas de Educação Física nas escolas em função de preparar peças com bom formato e bem lubrificadas no ritmo da engrenagem da máquina racional operante, é necessário ter em mente as palavras de Santin:

O cultivo desta sensibilidade nas escolas provavelmente não contribuirá para construir grandes fábricas, nem produzir grandes lucros. Da mesma maneira nāo contribuirá para construir arsenais de armas, nem revelará muitos ațletas para as olimpíadas e para os
pódios de coroamento... Mas poderá contribuir para criar uma paisagem mais humana, com
mais paz e bem-a mais paz e bem-estar. O professor de educação física e das práticas esportivas mais dọ que saber técnicas e estratégias, precisará saber brincar. Mais do que assumir a fisionomia de um comandante ou treinador, precisará inspirar-se na arte e nas orquestras.

\section{A QUESTĀO DO ESPORTE DE ALTO RENDIMENTO}

Aqui encontramos outro valor convergente, em termos de atitude, extraído das ações dos sujeitos constantes da pesquisa. As aulas de Educação Física, nas escolas, estruturam-se na prática esportiva com características
de um esporte competitivo, determinado pela obediência fiel às leis que o regulamentam, onde há a ausência da cooperação e a prevạlência do individualismo, visando a vitória, permitindo-se para isto explorar ou tirar vantagem dos mais fracos.

Durante algum tempo, chegou-se a afirmar que esta ação dos profissionais de Educação Física não educava. Grande equívoco, pois Bracht ${ }^{4}$ revela que esta forma de transmitir o esporte educa, se educação aqui significa levar o aluno a internalizar valores, normas de comportamento que lhe possibilitará se adaptar à sociedade vigente. E uma educação que leva ao acomodamento e ao fatalismo e não ao questionamento; uma educação que ofusca ou lança uma cortina de fumaça sobre as contradições de nọssa sociedade. Uma educação que nāo leva a formação de um aluno crítico, consciente e sensível à realidade que o envolve.

Interessante notar que essa atitude, presente nos sujeitos pesquisados, também se apresenta em grande escala junto aos agentes de formação profissional nos cursos de licenciatura em Educação Física. É necessário uma reflexão radical para reverter essa atitude.

\section{A QUESTÃo dO CORPO}

Os pesquisados deixaram transparecer em seu dia-a-dia na escola, uma Educação Física onde o corpo do aluno é visto como um objeto a ser melhorado em seu rendimento, onde as atividades físicas, em vários momentos, não são adequados aos corpos dos alunos e o corpo débil, não atlético, é 
ridicularizado ou desprezado e onde até se incentiva a exploração dos corpos "menos aptos".

Atitude preocupante, pois esta ação não permite ao aluno refletir sobre o seu corpo na direção da consciência corporal. Preocupante também, porque vários intelectuais, professores da área de educação física, já analisaram estas questões, já elaboraram importantes trabalhos e pesquisas nesta linha que, pelo observado, ainda não chegaram aos professores da rede escolar.

João Freire ${ }^{5}$ em sua viagem rumo ao universo do corpo, deixa claro seu desejo de que a Educação Física deveria deixar de ser técnica de adestrar homens para transformar-se em técnica que possibilitasse ao ser humano realizar o movimento com arte. Correr, andar, saltar e jogar são coisas executadas com arte, quando os meios utilizados para estas açōes são compreendidos.

Manuel Sérgio ${ }^{6}$, dissertando acerca dos valores ético-político do corpo, insiste na tese de que o homem não pode conhecer nem conhecer-se afrontando ou desprezando o corpo. A partir dessa premissa, ele enumera esses valores ético-políticos, dentre os quais destacamos: pelo corpo é que podemos atingir uma concepção global do Homem; pela linguagem corporal é que o Homem ganha um meio extraordinário de comunicação e diálogo; o corpo constitui, tanto interior como exteriormente, o primeiro e mais importante ponto de referência e de relação; o corpo não pode ser concebido como simples máquina ao serviço do espírito, porque sem ele o espírito é impensável; é através do corpo que o Homem capta seus limites, tantos os de ordem biologica como psicologica; as atividades corporais podem e devem, através do jogo e do esporte, exercitar a criatividade, a liberdade, a alegria e o bem estar.

Como se vê, há pessoas da área da Educação Física falando e escrevendo sobre o corpo, refletindo sobre a questão do corpo, propondo opções educativas a partir do trabalho da consciência corporal que, no entanto, passam despercebidas no dia-a-dia da vida da Educação Física Escolar.

\section{AS QUESTÓES DaS AUSÊNCIAS DE PRAZER E LUDICIDADE}

$\mathrm{Na}$ interpretação das unidades de significado revelada nas atitudes dos sujeitos pesquisados, deparamo-nos com a sensação de desprazer, tanto por partes dos alunos como dos professores. Assim, na análise geral encontramos o professor não tendo prazer em sua ação profissional, bem como a Educação Fisica senđò considerada " coisa séria " levando à ausência de ludicidade e prazer nas manifestações do corpo discente.

Manifesta-se então, via aulas de Educação Física na escola, a preocupação de Marcellino? , com a possibilidade da criança, hoje em dia, perder o direito ao ládico. Este autor lembra que, ao se fazer uma anallise da criança inserida na sociedade, verifica-se, de modo crescente, o furto da possibilidade de vivência do ládico na infância, pela negação temporal e espacial do jogo, do brinquedo e da festa. Nas nossas grandes cidades, as crianças não têm tempo e espaço para a vivência da infância, como produtora de uma cultura infantil. Lamenta-se que este fato, por atitudes de professores de Educação Física, também ocorra na escola como prejuizos inalienáveis aos direitos da criança e do aluno na escola.

Quanto ao prazer, é visível o valor da disciplina corporal na escola, onde a educação premiada É a da não criatividade, a da passividade, a do silêncio e a do desprazer. $O$ critério básico da Educação Escolar hoje é a palavra NÃO. Nada é permitido. Não pode conversar (Educação sem diálogo?); não pode rir (Educação sem ludicidade?); não pode sair da carteira ou da fila (Educação sem movimento criativo?).

Por sinal, alguns sujeitos da pesquisa revelaram seu desprazer em ministrar aulas, no momento em que se diziam azarados pois não estava chovendo e teriam que trabalhar. Atitude semelhante verificou-se junto ao corpo discente, onde bastava a saída do professor do local de aula para o ambiente se transformar, com os alunos brincando uns com os outros num clima de festa. Na volta do professor, o encanto se desfazia e a aula recuperava sua "seriedade" arrastada. 


\section{A QUESTÃo dO CONTEÚDO PROGRAMÁTICO DA EDUCAÇÃo FISICA}

Outra atitude permanente identificada na pesquisa diz respeito ao conteŕdo dessa Disciplina Curricular chamada Educação Física. Notamos que o mesmo "conteúdo", os "mesmos procedimentos de ensino", os mesmos "objetivos" propostos são vivenciados por alunos de diferentes faixas etárias, de diferentes séries, de diferentes conhecimentos ou experiências nessa Disciplina curricular.

Constata-se que, diferentemente das propostas dos outros componentes curriculares, a Educação Física não oferece uma seqüencialidade que acompanha o desenvolvimento do aluno nas várias séries. Tem-se a sensação de tudo se repetir, ano após ano, mês após mês, dia após dia e aula após aula.

Também fica evidente a constatação de que a Educação Física é apenas prática de atividades e estas, ainda, subjugadas por condições atmosféricas.

Este, portanto, é o retrato perspectival da Educação Física Escolar que se revelou na presente pesquisa, trazida hoje ao conhecimento dos colegas nesta mesa sobre a formação profissional.

E necessário, pelos resultados apresentados, que os agentes de formação profissional se preocupem, ao lado de refletir sobre teorias e transmitir conteudos, com a questão da atitude no contato com os alunos e na veiculação dos valores explicitados em suas atitudes.

Obrigado pela atenção ao relato da pesquisa.

\section{NOTAS E REFERENCIAS}

1. Detalhes da pesquisa podem ser encontrados em: MOREIRA, W.W. Educação ńsica escolar: uma abordagem fenomenologica. Campinas, Editora da Unicamp, 1991.

2. Veja: SANTIN, S. Educação física e esportes no 3o.grau: perspectivas filosóficas e antropológicas. In: PASSOS, S.C.E., org. Educação ñsica e esportes na universidade. Brasília, UnB-SEED/MEC, 1988. p.51-74.

3. Idem, ibidem, p.70.

4. Consulte: BRACHT, U. A criança que pratica esportes respeita as regras do jogo...capitalista. Rev. Brasileira de Ciências do Esporte, v.7, n.2, p.62-8, 1986.

5. Recomendada a leitura de: FREIRE, J.B. Rumo ao universo do corpo. In: OLIVEIRA, V.M. org. Fundamentos pedagógicos: educação física 2. Rio de Janeiro, Ao Livro Técnico, 1987. p.48-54.

6. Consulte: SERGIO, M. Filosofia das actividades corporais. Lisboa, Compendium, s.d. p.21-56.

7. Consulte: MARCELLINO, N.C. Pedagogia da animaçāo. Campinas, Papirus, 1990. 